\title{
LA ESCUELA Y LOS MODOS DE PRODUCCIÓN DE LA HEGEMONÍA*
}

EMILIO TENTI FANFANI*

Coordinador Area de Diagnóstico y Política Educativa, IIPE - UNESCO, Buenos Aires.

Profesor Universidad de Buenos aires emilio@iipe-buenosaires.org.ar

\section{Resumen}

La escuela y los modos de producción de la hegemonía Emilio Tenti Fanfani

El texto que a continuación se presenta refuta la tesis sustentada por Juan Carlos Tedesco en "Educación y hegemonía en el nuevo capitalismo". Sostiene que lo que a primera vista pareciera ser un debilitamiento de la "intención" de conquistar la "hegemonía" no es más que un síntoma de la más completa y hegemónica realización de la misma.

\section{Palabras claves}

Socialización, relaciones sociales, sociología de la educación.

\section{Summary}

This text refutes the thesis sustained by Juan Carlos Tedesco in "Education and hegemony in the new capitalism". It states that what at first sight would seem as a weakening of the intention of conquering the "hegemony" is no more than a symptom of the most complete and hegemonic realization of it.

\section{Key words}

Socialization, social relationships, sociology of the education

\footnotetext{
- Este texto se publica con autorización de la directora de la revista Propuesta Educativa de la FLACSO, Inés Dussel. Fue recibido el 6 de octubre de 2003 y arbitrado el 17 de octubre de 2003.
} 


\title{
LA ESCUELA Y LOS MODOS DE PRODUCCIÓN DE LA HEGEMONÍA*
}

\author{
EMILIO TENTI FANFANI \\ Coordinador Area de Diagnóstico y Política Educativa, IIPE - UNESCO, Buenos Aires. \\ Profesor Universidad de Buenos aires \\ emilio@iipe-buenosaires.org.ar
}

\begin{abstract}
"He nacido en un tiempo en que la mayoría de los jóvenes habían perdido la creencia en Dios, por la misma razón que sus mayores la habían tenido: sin saber por qué. Y entonces, porque el espíritu humano tiende naturalmente a criticar porque siente, no porque piensa, la mayoría de los jóvenes ha escogido a la Humanidad como sucedáneo de Dios (...) He considerado que Dios, siendo improbable, podría ser; pudiendo, pues, ser adorado; pero que la Humanidad, siendo una mera idea biológica, y no un significado más que la especie animal humana, no era más digna de adoración que cualquier otra especie animal.(...)

Así, no sabiendo creer en Dios, y no pudiendo creer en una suma de animales, me he quedado, como otros de la orilla de las gentes, en esa distancia de todo a que comúnmente se llama la Decadencia. La Decadencia es la pérdida total de la inconsciencia; porque la inconsciencia es el fundamento de la vida. El corazón, si pudiese pensar, se pararía"
\end{abstract}

Fernando Pessoa, en Libro del desasosiego. Seix Barral, Barcelona 1999; pp. 28-29.

\section{Introducción}

El artículo de Juan Carlos Tedesco, publicado en este número de la revista Propuesta Educativa es por demás provocador ("Educación y hegemonía en el nuevo capitalismo. Algunas notas e hipótesis de trabajo", citado en adelante como "JCT en Propuesta"). El famoso filósofo francés Gilles Deleuze, decía que él ya no valoraba a los textos por su "verdad" sino por el interés que lograba despertar en él. El criterio de verdad es más que discutible; en cambio, sabemos muy bien cuándo algo que oímos o leemos suscita en nosotros una inquietud y nos hace reflexionar.

Debo decir que la tesis del fin de la hegemonía en las sociedades capitalistas actuales no me satisface. Mi primera reacción fue responder la provocación (debería decir la invitación a la discusión) con otra provocación. En las líneas que siguen voy a sostener que lo que a primera vista pareciera ser un debilitamiento de la "intención" de conquistar "la hegemonía" (por parte de los poderosos de hoy) no es más que un síntoma de la más completa y "económica" realización de la misma. El supuesto subyacente es que el capitalismo no sólo domina en la realidad de los procesos de producción y distribución de bienes y servicios, sino que también domina sobre las conciencias.

Para fundamentar mi argumento recurriré al clásico concepto de dominación (de raíz weberiana), que tiene una cierta tradición en el pensamiento sociológico occidental. La forma de mi presentación es la más elemental. Como si se tratara de un diálogo aportaré una serie de ideas y reflexiones alrededor de dos ejes básicos. El primero tiene que ver con los modos de producción y reproducción de la hegemonía. El segundo con el papel de las instituciones de socialización (industria cultural, familia y escuela) en la formación de la subjetividad de los agentes sociales. Este esquema elemental y precario delata al

\footnotetext{
- Este texto se publica con autorización de la directora de la revista Propuesta Educativa de la FLACSO, Inés Dussel. Fue recibido el 6 de octubre de 2003 y arbitrado el 17 de octubre de 2003.
} 
menos dos cosas: una limitación personal y un deseo de continuar la conversación con Tedesco y con otros eventuales lectores.

\section{Modos de producción de la hegemonía}

Para fundamentar su argumentación, Juan Carlos Tedesco distingue dos momentos típicos del capitalismo. El primero, el industrial, era inclusivo o tendía hacia la inclusión. Pero para insertarse en las relaciones de producción capitalista había que poseer determinadas características que no estaban dadas en los sujetos. Por eso el Estado montó una empresa civilizadora, en cuya base estaban la escuela republicana y los maestros, encargados de incorporar una serie de hábitos mentales hechos de esquemas de distinción, apreciación y acción. La hegemonía tiene sentido en la medida en que se la necesita para "formar parte de" (la ciudad, el sistema productivo, la ciudadanía, etc.). Este esquema está presente en un trabajo anterior de Tedesco (2001) donde escribe que "la escuela obligatoria y universal, la escuela laica de la ley 1420, la escuela "sarmientina" -para decirlo en términos de su principal representante en Argentina-, era una escuela que se proponía difundir contenidos, pautas de conducta, valores y actitudes que estaban lejos (y en muchos casos eran antagónicos) con los valores y pautas culturales de la población a la cual atendía". Desde esta perspectiva la escuela tenía un sentido contracultural y "en términos políticos, expresaba la voluntad hegemónica de los sectores sociales que lideraban el proceso de modernización industrial capitalista.".

El concepto de hegemonía tiene un linaje. Desciende directamente del uso gramsciano del término y tiene su raíz sistemática en la clásica distinción weberiana entre poder y dominación ${ }^{18}$. Sin embargo, el planteamiento de Tedesco le agrega un elemento definitorio que sólo recupera una de las formas posibles de su producción y reproducción. En efecto, escribe Tedesco en un texto anterior (2001) que "Hegemonía significa, en este contexto, la voluntad (las itálicas son mías) de imponer al conjunto de la población, los contenidos culturales, la visión del mundo, propia del sector social dominante". En efecto, creo que la hegemonía no es sólo el producto de una voluntad o intencionalidad expresa de determinados actores colectivos, sino que también es el resultado de ciertos automatismos que resultan de la propia "interiorización de la exterioridad" (para usar una expresión de Habermas) que prescinde de toda voluntad e intencionalidad subjetiva ${ }^{19}$.

Según Tedesco, el capitalismo actual se encontraría en otra fase de su desarrollo ya que "el capitalismo es excluyente y tiene menos vocación hegemónica". Él mismo es consciente de que tiene que explicar tamaña afirmación en un momento histórico donde no sólo en la Argentina, sino a nivel mundial, predomina eso que en términos periodísticos se conoce como "pensamiento único". Lo que para algunos es la prueba del triunfo urbi et orbi del capitalismo, para Tedesco no es más que eso: la no disponibilidad de otras ofertas culturales y políticas distintas del "neoliberalismo". En sus propias palabras: "es

\footnotetext{
${ }^{18}$ Para Max Weber, "poder significa la probabilidad de imponer la propia voluntad, dentro de una relación social, aun contra toda resistencia y cualquiera que fuera el fundamento de esa probabilidad", mientras que "por dominación debe entenderse la probabilidad de encontrar obediencia a un mandato determinado contenido entre personas dadas" (Weber M., 1983, p. 43). Cabe recordar que el concepto de dominación se asocia con el de "legitimidad". La dominación implica "cooperación" (es decir, aceptación, consenso, credibilidad, etc.) del dominado en la producción y reproducción de la dominación. Y es aquí donde la dominación se encuentra con la idea gramsciana de hegemonía.

${ }^{19}$ En este sentido puede resultar útil revisar la contribución de Norberto Elias cuando analiza los procesos de conformación del "habitus psíquico" típico de las sociedades capitalistas. En este caso, la formación de una nueva subjetividad no es el resultado de ninguna intencionalidad, sino del efecto de los nuevos sistemas de interdependencia (hábitat urbano, separación de los productores de los medios de producción, etc.) que estructuran la vida de los individuos (al respecto ver Elías, N., 1983).
} 
preciso no confundir pensamiento único con pensamiento hegemónico. El 'pensamiento' neoliberal es único porque no aparecen alternativas, pero no es hegemónico porque no convence y no es capaz de incluir a todos. Al pensamiento único no le interesa la adhesión. El nuevo capitalismo no se plantea convencer. Simplemente deja afuera y, en ese sentido, es incompatible con la democracia y es incompatible con la política." (JCT en Propuesta). Todo parece indicar que el capitalismo "puede dejar afuera" a masas significativas de individuos (por ejemplo en la Argentina son completamente excluidos del mercado de trabajo capitalista casi un cuarto de la población económicamente activa) sin comprometer el equilibrio general del sistema. No habría interés en "convencer" a los excluidos de las bondades del mercado. Sin embargo, existen evidencias que muestran lo contrario: los excluidos de hoy quieren ser incluidos... en el sistema capitalista. Por otra parte, es por lo menos arriesgado afirmar que los excluidos son al mismo tiempo "indiferentes" al capitalismo. Por el contrario, los excluidos de hoy no son como los precapitalistas de la primera etapa del desarrollo industrial. A esos había que "civilizarlos" incorporándolos a los valores y costumbres de la cultura urbana industrial. Para ello se montó esa gigantesca y relativamente exitosa empresa civilizadora que fue la escuela de Estado.

Hoy, ese ímpetu educativo del primer capitalismo parece haberse debilitado. Cada vez cuesta más que el Estado financie y expanda los servicios educativos de calidad. Cada vez interesa más la escolarización y menos el desarrollo de conocimientos, competencias y valores en las personas. ¿Esta es la evidencia mayor de que "al sistema capitalista" no le interesa influir sobre la subjetividad de los excluidos del mercado de trabajo (aunque no del consumo de bienes materiales y simbólicos del capitalismo) o bien significa que la socialización necesaria para el control de la población se realiza por otras vías, menos formales y explícitas y por lo tanto menos "políticas"? Todo invita a inclinarse por esta segunda explicación, a condición que se hagan algunas precisiones conceptuales.

La primera tiene que ver con el concepto mismo de hegemonía y sus raíces en la teoría social y política clásica y contemporánea. En segundo lugar, habría que relacionar el concepto de hegemonía con el de dominación, en el sentido weberiano de la expresión. Al mismo tiempo, es preciso realizar algunas consideraciones básicas acerca de las modalidades típicas y de las agencias constructoras de subjetividad y por lo tanto de hegemonía.

Quien usa en forma sistemática este concepto es Antonio Gramsci. El entendía, como Max Weber, que un sistema político relativamente estable no funciona sólo con el "monopolio de la violencia física" (la coerción en términos gramscianos). Una condición de estabilidad del sistema requiere de otro componente igualmente importante, que fue enfatizado en el modelo weberiano de análisis de los sistemas de dominación. Éstos, por definición necesitan del consentimiento de los dominados. No olvidemos que para Weber la dominación se diferencia del poder, porque mientras éste consiste en la probabilidad de imponer un mandato independientemente de la voluntad o resistencia del "súbdito", la dominación se define como la probabilidad de encontrar obediencia para mandatos específicos. La obediencia (o el consentimiento, el consenso, etc.) es el fundamento de cualquier sistema de dominación y puede encontrar distintas fuentes de sustentación (la tradición, el carisma, un ordenamiento legal, etc.). Es conocida la definición gramsciana del Estado como "hegemonía acorazada de coerción", que no es otra cosa que dominación legítima en términos weberianos.

El planteamiento anterior es retomado por Pierre Bourdieu (1996) cuando define al Estado como el ámbito institucional que detenta dos monopolios: el de la violencia física y el de la 
violencia simbólica, entendida ésta última como la capacidad de imponer significados y de hacerlo en forma legítima. En efecto, el Estado tiene este poder de oficializar, de definir los límites de un territorio, de decir cuántos habitantes lo pueblan, de definir la hora oficial, de dar un sentido a determinadas relaciones sociales (de propiedad, de familia, etc.). El Estado, aun prescindiendo de toda intencionalidad, mediante las realidades que es capaz de crear, contribuye al desarrollo de ciertas categorías de percepción y valoración del mundo y de este modo contribuye a la producción de la subjetividad de los agentes sociales.

"Aún el tirano debe dormir", decía Hobbes. En otras palabras, hasta la más cruel de las dictaduras, la que se basa casi exclusivamente en el uso o amenaza de uso de la fuerza física también requiere un mínimo de legitimidad. Por lo menos alguien debe creer y querer o tener interés en mantener al tirano: aquellos encargados de su propia seguridad personal. En otras palabras, todo régimen político puede ser clasificado en un espacio estructurado alrededor de dos polos típicos: el de la hegemonía (la legitimidad, el consenso, hoy diríamos la democracia republicana) y el de la coerción o fuerza pura (el poder desnudo). Por eso Gramsci definía al Estado como "hegemonía acorazada de coerción".

Desde esta perspectiva afirmar que hoy el régimen capitalista no tiene interés en la hegemonía es por lo menos arriesgado. Todo régimen político/social busca la legitimidad, aunque más no sea para ahorrar el costo del uso sistemático de la fuerza, así como sus limitaciones estructurales para hacer que los agentes se impliquen en el proceso capitalista $^{20}$. Pero si es así, ¿cómo no reconocer que luego de la caída del muro de Berlín y el fin de los socialismos reales el capitalismo reina en la realidad y en las conciencias de la mayoría de los países desarrollados y de mediano desarrollo (como la Argentina)? El supuesto fin "de las ideologías" (que probablemente no sea más que el fin de ciertas ideologías anticapitalistas) induce a pensar en el fin de la hegemonía. ¿Por qué? Porque los intelectuales tendemos a interesarnos más por las ideologías como doctrinas sistematizadas que en las creencias como inclinaciones incorporadas.

Entonces hay que volver a preguntarse en qué consiste concretamente la hegemonía. ¿Cómo se manifiestan hoy esas concepciones del mundo que orientan la acción de los humanos? Voy a sostener que se apoyan en pequeñas y poderosas fuerzas: las creencias incorporadas que adquieren la forma de esquemas literalmente incorporados que operan en los cuerpos de los individuos) del los cuales no tenemos una conciencia acabada ("el corazón, si pudiese pensar, se pararía", escribía Pessoa). Estas creencias (en las virtudes del mercado y en los defectos del Estado, por ejemplo) no son como las doctrinas o las ideologías, que tienen un carácter sistemático y que uno adopta, 0 eventualmente desecha, en forma consciente y deliberada.

\footnotetext{
${ }^{20}$ La hegemonía como legitimidad es una condición de la reproducción del sistema capitalista y sus protagonistas principales, los capitalistas y la fuerza de trabajo (la "población económicamente activa") necesitan encontrarle un sentido al rol que les toca jugar. Como dicen Boltanski y Chiapello "el capitalismo es, en varios aspectos, un sistema absurdo" ya que "los asalariados han perdido la propiedad sobre el resultado de su trabajo y la posibilidad de llevar una vida activa fuera de la subordinación. En cuanto a los capitalistas, se encuentran encadenados a un proceso sin fin e insaciable, totalmente abstracto y disociado de la satisfacción de las necesidades de consumo, aunque estas fueran de lujo. Para estos dos tipos de protagonistas, la inserción en el proceso capitalista carece singularmente de justificaciones". Por otra parte, "la motivación material" (la necesidad de satisfacer necesidades), en sí misma, "se revela como poco estimulante". De allí se deduce que asalariados y capitalistas necesiten encontrarle un "espíritu al capitalismo. (...) Nosotros llamamos espíritu del capitalismo a la ideología que justifica el compromiso en el capitalismo" (Boltanski L. y Chiapello E.; 1999, pp. 41 y 42). 
En este sentido, el planteamiento de Tedesco tiene la virtud de obligar a reconocer la especificidad del contexto actual en cuanto supone el predominio de un nuevo modo de producción de la dominación, distinto del modo tradicional típico del primer capitalismo. Desde esta perspectiva, más que de ausencia de hegemonía, estaríamos en presencia de otro modo de producción y reproducción de la misma que tiene las siguientes características básicas:

a) es tácito e indirecto, pero tanto o más efectivo que cualquier programa explícito de inculcación (típico del esfuerzo "civilizador" de los primeros sistemas educativos del capitalismo nacional/estatal). En las condiciones actuales, los sistemas de producción y difusión de significados, al actuar en el marco del mercado y no perseguir adoctrinar ni convencer, sino vender y hacer dinero, terminan convenciendo y adoctrinando a través de la formación de una "cultura popular" (un "gusto", un sistema de preferencias, etc.) que alimenta una demanda de productos que ellos están predispuestos a satisfacer, en un círculo que no se rompe sin crítica y decisión colectiva. En otras palabras, los medios masivos de comunicación educan sin proponérselo.

b) Puede prescindir de la escuela y además es más "económico". Por eso algunos hasta han llegado a proponer el liso y llano desmantelamiento de esa vieja institución y su reemplazo por el autoaprendizaje sostenido en las nuevas tecnologías de la información y la comunicación.

Según el lenguaje sin eufemismos de Lewis Perelman (1995), un entusiasta del hiperaprendizaje, "la enseñanza pública actual, en tanto que institución, es una innovación del siglo XIX, elaborada sobre el modelo de la fábrica y destinada a una economía industrial, ahora bien, para la economía moderna basada en las tecnologías de la información de punta, los dos son casi tan vitales como la carreta o la fragua". Para que no queden dudas de su valoración de la escuela como institución agrega que "la educación es el último gran bastión de la economía socialista. La escuela y la universidad son casi tan productivas e innovadoras como los kolkhozes soviéticos". El desmantelamiento de la escuela no se explica por el desinterés del capitalismo actual por la hegemonía o el conocimiento. Por el contrario, la escuela está condenada porque es pedagógicamente obsoleta y puede ser reemplazada por otros dispositivos de transmisión cultural ("Genéticamente, el ser humano está programado para aprender mediante el método activo. Es a través de lo vivido y no en un salón de clases donde el hombre aprende mejor"). Por otra parte, la escuela no sirve ni siquiera para lograr la integración social, pero Perelman advierte: "No se engañe. Investigadores han demostrado que la escuela tiene efectos nefastos sobre aquella: el fracaso escolar, que afecta a la mayoría de los estudiantes, los hiere en su amor propio, mientras que el éxito le proporciona a los pocos elegidos una sensación de seguridad y un sentimiento de superioridad que les puede jugar en contra". Por eso no hay nada mejor que el "hiperaprendizaje".

Pero si faltara un argumento para justificar la muerte de la escuela ${ }^{21}$ éste lo proporciona el liberalismo. El hiperaprendizaje (con su parafernalia de sistemas expertos, redes de Internet, sitios, asistentes, instructores, programadores, expertise "a la carta", softs para el aprendizaje especializado, ofertas de aprendizaje just-in-time, etc., etc.) constituye un gigantesco mercado. "En los Estados Unidos -se entusiasma Perelman-, el hiperaprendizaje podría generar un mercado que supera en un $50 \%$ al de la industria mundial de la informática actual. Por otra parte, mientras que la reforma de la educación

\footnotetext{
${ }^{21}$ De paso es oportuno recordar que la escuela sobrevivió a varias condenas a la pena capital (¿Cuántos se acuerdan hoy de Iván Illich?).
} 
ha estado signada por una larga y triste historia de iniciativas gubernamentales infructuosas, esta estrategia se beneficia con el motor del liberalismo".

La vieja función de socialización política y de producción de ciudadanos hoy corre por otros carriles, se resuelve por otros medios: justamente la industria cultural y la educación de las cosas. Tampoco se necesita un ejército civilizador. El mercado educa e inculca esos principios básicos de una visión del mundo, ese sentido de lo posible y de lo imposible, que constituye el universo básico del "hombre (y la mujer) de este tiempo". Las evidencias están a la vista. En la Argentina actual, la mayoría de los ciudadanos comparte un conjunto básico de categorías de percepción y apreciación de las cosas de la economía, la política y la cultura que son "funcionales" para la reproducción de los principios que estructuran a la sociedad actual.

La mayoría de la población cree en el mercado como mecanismo más eficiente (¡casi único!) de asignación de recursos, cree en la "ley de la oferta y la demanda", en el carácter sagrado de la propiedad privada, en un Estado que es corrupto, burocrático que tiene que ser mínimo y no intervenir en la economía, etc., etc. Es hasta ingenuo preguntarse "quién enseñó" estos contenidos, en qué currículo y en qué programa escolar estaban incluidos. En verdad, podríamos decir que no los enseñó (en el sentido fuerte de una acción pedagógica formal e institucionalizada) nadie y fueron aprendidos por la mayoría. Porque las "cosas sociales" educan a través de la experiencia (la vida, el trabajo, la posición que se ocupa en los mercados, etc.). Y los medios masivos de comunicación (con sus "comunicadores exitosos") hicieron el resto: convirtieron una experiencia en una doctrina, lo cual refuerza la inculcación al racionalizarla, al convertirla en un conjunto sistemático de razonamientos, de argumentaciones, de principios, etc., que se pueden dominar en forma más o menos coherente. Mientras que algunos son "intuitivamente" neoliberales, otros son capaces de recitar un catecismo, algo así como una especie de basic liberalism hecho de una mezcla de jerga y sentido común, frases hechas, etc. Por último, están los "gurúes" y referentes intelectuales. Esos sí son capaces de argumentar con lenguajes más sofisticados, incluso utilizando complejos modelos matemáticos.

Toda esta socialización política que hoy configura un consenso real alrededor de ciertos temas básicos de la economía, la sociedad y la política, no transcurrió en la escuela ni conforme a ningún programa pedagógico didáctico. Por el contrario, podríamos decir que el currículo escolar argentino actual es contracultural (hasta cierto punto, por cierto) en la medida en que no es lisa y llanamente neoliberal. Un ejemplo basta para corroborarlo. Mientras la sociedad actual privilegia los valores materialistas (la riqueza, la ganancia, el consumo ostentoso, la frivolidad, etc.) por sobre los del espíritu (las cualidades morales o éticas, el conocimiento, la sabiduría, las artes, la seriedad, etc.) el currículo oficial de la escuela (y la propia tradición cultural de la mayoría de los docentes) privilegia los segundos. Mientras en la sociedad prima una cierta tolerancia por las desigualdades sociales, en la escuela predomina la visión de una sociedad igualitaria con diferencias predominantemente funcionales, pero igual dignidad para todos. Y podríamos seguir con los ejemplos.

En síntesis, aquí quiero defender la tesis de la irrelevancia creciente de la escuela como ámbito de producción de hegemonía cultural y política. Sin embargo, esta constatación no autoriza a la lisa y llana condena de la escuela. Esta sigue siendo el único ámbito donde es posible realizar ese trabajo que requiere toda transmisión cultural exitosa. Pero volveremos sobre el sentido de la escuela en la última sección de este artículo. 


\section{El "misterio" de la hegemonía capitalista con exclusión social}

Tedesco nos recuerda que "el capitalismo industrial era un capitalismo inclusivo que establecía vínculos entre todos los sectores sociales a través de relaciones de explotación y de dominación. El nuevo capitalismo, en cambio, genera fenómenos de exclusión, que se definen, precisamente, por la mayor precariedad, la ausencia o la ruptura de los vínculos" (JCT en Propuesta). Más allá de la crítica que merece el discurso de la "exclusión social", éste refleja una problemática bien real. Ahora bien, la relación entre exclusión y hegemonía es de una importancia primordial. Los hechos indican que el capitalismo actual puede combinar, hasta cierto punto y de un modo muy conflictivo dosis crecientes de exclusión y desigualdad con una dosis significativa de legitimidad. Al respecto, Boltanski y Chiapello (1999) hablan de una conflictiva convivencia entre "un capitalismo regenerado y una situación social degradada" ¿Cómo se explica esta contradicción? En gran medida esta contradicción está en la base de toda la conflictividad presente y futura de las sociedades con grandes dosis de exclusión social.

La sociedad argentina actual es un caso paradigmático. No estoy en condiciones de responder en forma sistemática a esta pregunta fundamental que surge de la lectura del texto de Tedesco. Sin embargo, estas dosis nunca antes conocidas de exclusión y desigualdad social, al menos hasta el presente no han producido una ruptura en el sistema de creencias básicas de la mayoría de la población. Esta, en su gran mayoría, demanda una solución (una "inserción") en el marco del sistema capitalista actualmente dominante, aunque nadie puede prever cuáles serán los escenarios futuros.

En síntesis, el escenario actual se caracteriza por una combinación conflictiva de exclusión, desigualdad y legitimidad relativa, pero suficiente.

Por otra parte, la presencia de la exclusión social en el contexto nacional e internacional convive con un proceso de signo contrario. En efecto, ¿qué quiere decir que el capitalismo actual se caracteriza por la ausencia de vínculos? Si uno recuerda las tesis de Norberto Elias sobre la lógica de la génesis y desarrollo del capitalismo, la "mundialización capitalista" sería precisamente lo contrario: aquellos que están insertos en el capitalismo mundial se caracterizan precisamente por estar insertos en un sistema o red de interdependencias objetivas mucho más extensos y complejos que los previamente conocidos $^{22}$.

Si estos argumentos son plausibles, las ecuaciones "inclusión-hegemonía", "exclusióndebilitamiento de la hegemonía" son un tanto problemáticas y merecerían mayores precisiones. En primer lugar, porque habría que discutir sobre el sentido de la relación entre ambos fenómenos. Uno podría dar completamente vuelta el argumento y decir que a mayor exclusión, más necesaria se hace la hegemonía... ya que a los excluidos no deben constituir un problema, deben aceptar esta condición como natural, caso contrario se convierten en un factor de desestabilización del orden. Pero esto vuelve mucho más necesario el control de los excluidos, que si tuviera que basarse solamente en la represión; es decir, en la antítesis y complemento de la hegemonía, como diría Gramsci, sería antieconómico y por último pondría en peligro la reproducción misma del sistema.

\footnotetext{
${ }^{22}$ Por ejemplo, el productor de uva de Mendoza no tiene por qué tener conciencia de que la viabilidad de su negocio, el precio de su producto, etc., dependerá de situaciones y factores (leyes y regulaciones, derechos de importación, controles sanitarios, publicidad, gustos, etc.) que actúan en mercados y contextos de otros países que le son totalmente desconocidos).
} 
En realidad, por ahora, me inclino a pensar que existen dos "novedades": la primera es que a mayor exclusión y desigualdad mayor es la necesidad de hegemonía -entendida como consenso, como legitimidad, etc. -; la segunda es que esta hegemonía hoy no precisa de acciones explícitas de inculcación, al estilo clásico del primer capitalismo: es decir, un ejército de maestros y escuelas que tienen por función "civilizar", inculcando en la población un habitus determinado: el habitus capitalista. Hoy, hay hegemonía por el peso de las cosas.

El desempleo y el hambre son dos grandes disciplinadores sociales, al menos hasta tanto no se construya una hegemonía alternativa, o lo que es lo mismo, un proyecto alternativo de sociedad. Hoy, el mercado es tan superior (en la conciencias de la mayoría de los argentinos urbanos) a cualquier otro modo de organización de la sociedad, que ni siquiera es posible pensar en medios alternativos: éstos no existen en la realidad... ni en la conciencia. Exagerando la cuestión o se es capitalista o se es precapitalista, como es el caso de las comunidades indígenas y otras sociedades primitivas que todavía se conservan en ciertos rincones del planeta (configuraciones sociales que en muchos casos ni se enteraron de que existe el mercado capitalista, la moneda, el Estado nacional, etc.).

En términos sociológicos y en casos extremos, la dominación del mercado sobre el Estado (éste es el núcleo duro de la hegemonía política y social) se ha convertido en algo tan fuerte y "natural" (en verdad se ha naturalizado) como la del hombre sobre la mujer. Es probable que la homología estructural entre ambas dominaciones sea una exageración, pero al menos merece ser explorada y desarrollada con mayor profundidad.

\section{El debilitamiento de las instituciones de socialización}

\section{a) El sistema de producción y difusión de bienes culturales}

Según Tedesco, "la debilidad de la vocación hegemónica del nuevo capitalismo está asociada a los nuevos patrones de funcionamiento de las instituciones responsables de la producción y la distribución de bienes culturales. En el capitalismo industrial, la cultura se basaba en instituciones que funcionaban sobre la base de la lógica de la oferta. La escuela -y también la TV general- estaban basadas en ofrecer a todos un mismo producto y esta oferta tenía, por eso, un fuerte poder homogeneizador. En esta lógica y en este poder se expresaba la voluntad hegemónica de los sectores dominantes. Los nuevos mecanismos culturales, en cambio, se basan mucho más en la lógica de la demanda" (JCT en Propuesta). El argumento reproduce el tema de la primacía de la oferta o de la demanda para rendir cuentas de lo que produce y distribuyen los medios. Al respecto, creo que hay que saldar esta discusión no en favor de la demanda o de la oferta, como dimensiones separadas, sino profundamente imbricadas.

Toda oferta al mismo tiempo responde y crea demanda. En términos idealtípicos la cuestión tiende a plantearse en términos dualistas. Según algunos, manda la oferta. Esta sería capaz de crear su demanda de la nada. En el otro polo estarían quienes plantean la primacía de la demanda. La oferta cultural es una simple respuesta a la demanda de los "clientes". Esta visión esquemática de la oferta y la demanda es sólo un constructo lógico que no tiene correspondencia en la realidad. En verdad, como decía Weber, no puede comprenderse el éxito de los profetas y sus profecías sin tener en cuenta que esta oferta se basa en una especie de demanda latente. En otras palabras, todo "verbo nuevo", para tener éxito tiene que caer en un terreno propicio, requiere condiciones sociales de 
recepción; en otras palabras, supone una demanda objetiva. Ni siquiera en este caso existe predominio excluyente de la oferta ${ }^{23}$.

Según nuestro autor, "Internet, la TV por cable (y la escuela basada en los mecanismos de responder a las demandas del "alumno-cliente"), invierten el esquema existente en el capitalismo industrial $y$, en ese sentido, expresan la escasa vocación hegemónica del nuevo capitalismo". Pero la industria cultural tiene una gran capacidad de producir sus propios clientes, generar necesidades y demandas y, al mismo tiempo, inculcar criterios de percepción y valoración de los productos culturales que lanza al mercado. Por lo que la tesis del predominio de la demanda es al menos discutible. En verdad, puede afirmarse que lo que existe es otra cosa: un debilitamiento de las viejas instituciones de socialización, tales como la familia y la escuela y su sustitución por el consumo y los medios masivos de comunicación, cuyos productos no pueden ser reducidos a simples respuestas de una demanda del consumidor (el televidente, el usuario de Internet, etc.) ni a una lisa y llana creación de la nada. Por otra parte, la concentración de estos medios en pocas manos tiene como consecuencia fortalecer el lado de la oferta para conformar una demanda a su imagen y semejanza, o al menos a imagen y semejanza de sus intereses: la ganancia. Por eso no puedo más que acordar con Tedesco cuando escribe que "En este nuevo capitalismo, la cultura popular o " masiva » se produce cada vez más a través de industrias que responden a la lógica del mercado y del beneficio. A diferencia de la cultura popular de la sociedad industrial, que se producía en el seno de la comunidad, de la clase social o del grupo profesional, la cultura popular actual está mucho más asociada directamente a las industrias culturales" (2001).

\section{b) La familia y su autoridad pedagógica}

Por otra parte, Tedesco agrega otro obstáculo a la transmisión intergeneracional de la cultura. Este se originaría en "la crisis de autoridad que afecta a las instituciones clásicas de socialización. En este sentido, "el principio democrático" instalado en el corazón de la familia destruyó los fundamentos de la autoridad paterna y se constituyó en un obstáculo para el ejercicio de la dominación simbólica.

La crisis o ausencia de hegemonía tendría otras raíces en la incapacidad creciente de las familias para garantizar la transmisión de un patrimonio cultural a las nuevas generaciones. Las evidencias las proporcionarían "diversos estudios (que) indican que son cada vez más los adultos que consideran que no deben transmitir a sus hijos una determinada visión del mundo sino la capacidad para elegir y formar autónomamente su propia concepción" (JCT en Propuesta). Sin embargo, es preciso recordar que la herencia cultural nunca es el resultado de una voluntad deliberada, explícita y consciente de transmitir. En verdad, todos los estudios acerca de la primera socialización que se realiza en la familia muestran que la transmisión es tanto más efectiva cuanto menos intencional es.

\footnotetext{
${ }^{23}$ Un ejemplo típico lo constituye la explicación del peronismo. El éxito de la propuesta peronista no se explica por las cualidades intrínsecas del programa justicialista como oferta política (o por las cualidades excepcionales de su líder. En cierta medida el peronismo respondía a una demanda; es decir, a determinadas condiciones sociales tales como, las características del proceso de sustitución de importaciones, los procesos de urbanización y asalarización de la fuerza de y sus estados de necesidad, la inadecuación de la vieja legislación laboral, los déficit de representación del sindicalismo tradicional, etc., etc. Todas estas condiciones constituían el terreno fértil sobre el que cayó la simiente peronista. Aquí también una oferta oportuna y adecuada se juntó con una demanda implícita y objetiva de representación. Pero la historia demuestra que también existen ofertas fracasadas y oportunidades no aprovechadas.
} 
Si la transmisión intergeneracional de un acervo cultural es cada vez menos posible, ¿cómo pensar en la posibilidad de existencia de una hegemonía? Sin embargo, considero que es más apropiado decir que lo que está en crisis es una idea de transmisión como acto consciente, como objetivo que requiere estrategias, recursos, tiempos, un contenido explícito, estrategias sistemáticas y "disciplinarias", "racionales" o "formales" de inculcación, etc. Pero lo que no está en crisis porque no puede estarlo es lo que en el siglo XIX se llamaba "la educación objetiva o educación de las cosas". En este sentido, la casa donde se habita, el lugar que se ocupa en la familia, el tipo de familia, el barrio, la lengua que se habla, la comida que se come, los lugares que se transita, la ropa que se viste, etc. "educan"). Precisamente esto sucede cuando no se reconoce cuánto de no institucional, de no formal, de espontáneo, de "natural" y no calculado tiene el proceso de socialización. La confusión puede encontrar origen en una especie de sobrevaloración de una visión pedagogicista de la transmisión cultural: que supone "ámbitos institucionales" especializados, un contenido a transmitir (una "referencia absoluta"), las mediaciones, etc. Cuando se tome conciencia de que lo más importante en el proceso de socialización transcurre en el ámbito de lo no pensado y no planificado, entonces la idea de crisis del proceso de socialización tendrá un carácter más relativo.

Los cambios en las formas de ejercicio de la autoridad pedagógica (en la familia, la escuela, etc.) comentados por Tedesco, me sugieren una reflexión. Es probable que los fundamentos y las formas de la autoridad pedagógica familiar hayan sufrido transformaciones sustantivas como efecto de varios factores combinados, tales como la modificación de los equilibrios de poder entre generaciones y entre los géneros y la presencia de otras agencias de socialización tan o más efectivas que la familia, tales como las industrias culturales ${ }^{24}$. Por otro lado, es probable que hoy en día sea la fuerza de las cosas la que educa y no la intencionalidad de un padre y una madre que se proponen educar. Es probable que la socialización de las nuevas generaciones ya no obedezca a un proyecto sino que se desenvuelva conforme a otra lógica y con base en otra división del trabajo entre las instituciones sociales. Difícilmente podría sostenerse que "los padres" en general, ya no tienen autoridad, que los niños "se hacen a sí mismos", que ellos "pueden elegir" en materia cultural, al menos en lo que es más importante, como la lengua, la religión y un conjunto sistemático de creencias que funcionan como determinantes de la acción. Por otra parte, no hay que confundir el fenómeno cierto e importante de la modificación profunda que se ha registrado en el equilibrio de poder entre las generaciones (Elias, N., 1998), con una lisa y llana desaparición de la dominación intergeneracional. Los derechos del niño, en efecto, invaden la esfera privada, modifica expectativa y prácticas, tanto de los adultos como de los niños, pero esto no permite concluir en la desaparición de la autoridad pedagógica familiar y en la existencia de una "red integrada por individuos solidarios pero iguales" donde se registran intercambios, pero no transmisión, porque no hay nada que transmitir, ni están dadas las condiciones para ello.

Por otra parte, y para agregar mayor complejidad al asunto, Tedesco dice que "la crisis de la función de transmisión inter-generacional está asociada a una de las características más importante del contexto cultural del nuevo capitalismo: la concentración en el presente". Al respecto, puede decirse que esto es más plausible en las condiciones críticas actuales que vive la sociedad argentina. La crisis, entre otras cosas, tiende a

\footnotetext{
${ }^{24}$ La investigación acerca de las transformaciones en las configuraciones familiares y sus impactos en el proceso de socialización referido a diferentes categorías sociales (según nivel socioeconómico, hábitat, capital cultural, etnia, religión, etc.) es más que escasa en la Argentina. Esta escasez de evidencia empírica acerca de la diversidad de situaciones que se presentan constituye un obstáculo para conocer tanto la intensidad como el sentido de los cambios en curso.
}

Digitalizado por RED ACADEMICA 
asentar la pretensión monopólica del presente. Sin embargo, es preciso recordar que todo cambio, por más radical que parezca, se inscribe en un horizonte de continuidad. Las raíces existen aunque no tengamos conciencia de ello. Hay mucha historia muerta que se apodera de lo vivo. Y esta historia está en las cosas de la sociedad (sus recursos, su infraestructura, su sistema de regulaciones, etc.) y está en las mentalidades de los agentes, aunque ellos no tengan conciencia de ello. Es más, la historia es tanto más efectiva cuanto menos conocida es. Por otra parte, no está demás recordar con Borges que "la tradición es obra del olvido y de la memoria" y que "el propósito de abolir el pasado ya ocurrió en el pasado y-paradójicamente- es una de las pruebas de que el pasado no se puede abolir".

Los cambios que se viven son tan profundos y vertiginosos que muchos posmodernos tienden a decretar el fin de toda idea de rutina y reproducción social y tienden a pensar en la historia actual como creación permanente. Desde esta perspectiva, el fin literal de la historia como sucesión de interdependencias, sería por añadidura el fin de todo determinismo y el advenimiento de un supuesto "agente libre y liberado de su pasado", y por lo tanto liberado de toda necesidad. Sin embargo, toda la evidencia sociológica indica que lo que sucede hoy no es indeterminado, sino que se explica por ciertas cosas que sucedieron antes. La pérdida de la idea de proceso, es al mismo tiempo pérdida de sentido. Pero nadie puede liberarse del pasado (ni de los condicionamientos sociales que incluso explican muchos pensamientos y posiciones intelectuales) .

Seguramente, Juan Carlos Tedesco acordará conmigo que los humanos nunca fuimos el producto exclusivo de la escuela, la familia, o las otras instancias formales de socialización (la Iglesia, etc). La vida misma, o sea, la experiencia, "las cosas" y todo el sistema de condiciones e interdependencias que estructura la vida de un sujeto desde que nace, educan tanto o más que la familia y la escuela. En verdad, se dice que nuestros padres nos educaron cuando menos tenían intenciones de hacerlo, mediante el ejemplo, las experiencias que nos hacían vivir y con intervenciones no intencionales, pero de tremendo impacto constructivo (esas medias palabras, esas miradas, esos límites e inducciones sutiles que tienen un gran poder preformativo).

Lo mismo podríamos decir de la familia ampliada, los amigos, los vecinos, el barrio, la ciudad, el trabajo, la geografía, etc., etc. Las cosas sociales con todas sus interdicciones y facilitaciones e inducciones, con todas sus múltiples sugerencias van formando en los sujetos una serie de predisposiciones e inclinaciones que conforman una subjetividad... todo sin que nadie se dé realmente cuenta: ni los adultos ni las nuevas generaciones. $Y$ esa educación no obedece a ningún programa preestablecido (con todos sus currículos, objetivos generales y específicos, "contenidos procedimentales, actitudinales y cognitivos", con toda su parafernalia de dispositivos pedagógicos, didácticos, curriculares, institucionales, etc.). Esa educación implícita deja sus huellas en lo más profundo y duradero de la subjetividad: sobre el cuerpo del agente, que se convierte en un cuerpo educado (sumiso, humilde o altivo y orgulloso, saludable o "sufrido", etc.); es decir, predispuesto a hacer o no hacer determinadas cosas a hacerlas o no hacerlas de cierta manera, etc. ${ }^{25}$ Esta educación de las cosas y de la experiencia es la que transmite y garantiza una herencia a través de un lenguaje y unos criterios de acción y valoración que se instalan en el cuerpo) (Tenti Fanfani, E., 2002).

\footnotetext{
${ }^{25}$ Respecto del saber en el cuerpo Borges (1980, p. 155) escribió que "en lo corporal, la inocencia es una necesidad de los actos físicos. Nuestro cuerpo sabe articular este difícil párrafo, sabe tratar con escaleras, con nudos, con pasos a nivel, con ciudades, con ríos torrentosos, con perros, sabe atravesar una calle sin que nos aniquile el tránsito, sabe engendrar, sabe respirar, sabe dormir, sabe tal vez matar: nuestro cuerpo, no nuestra inteligencia".
} 
De modo que ese self made man que nos presentan ciertas teorías "post" contemporáneas (el fin del determinismo, el fin de la historia, la posmodernidad, el fin de las instituciones, etc.) probablemente no sea más que una proyección de ciertos intelectuales $^{26}$. Esta especie de subjetivismo puede no ser más que un efecto de academia, propio de esos hombres que se imaginan como hiperreflexivos y libres de todo determinismo. Por no tener en cuenta cuáles son las condiciones sociales bien reales y concretas que hacen posible la emergencia de este tipo de imágenes libertarias, los intelectuales tienden a proyectar al conjunto de la humanidad la propia idea que se hacen del sujeto y de sí mismos. No está demás recordar que la reflexividad es una competencia potencial de los individuos cuyo despliegue exige determinados recursos y condiciones sociales (liberación de la necesidad, tiempo para pensar, recursos expresivos incorporados, existencia de interlocutores, etc.) que no están garantizadas para todos los agentes sociales.

\section{c) El sistema escolar y la producción de la subjetividad}

Hay ciertas cosas que es preciso aprender (en especial el aprender a aprender, hecho de competencias genéricas y poderosas tales como el dominio de los lenguajes naturales y simbólicos, la lógica científica de las ciencias naturales y humanas, etc.) y que sólo allí se pueden aprender; es decir, que no se aprenden ni en la familia (por más capital cultural que dispongan sus miembros adultos) ni en todas las instancias de producción y difusión de bienes culturales. Si las clases dominantes de los sistemas capitalistas actuales se desinteresan progresivamente por la educación pública, no es por desinterés en la hegemonía, sino por otros motivos:

a) porque creen que se trata de una institución obsoleta e irracional que tiene que ser reemplazada por otros mecanismos pedagógicos (las tecnologías modernas de la información y la comunicación).

b) porque el reemplazo de la escuela, además de aconsejable desde el punto de vista tecnológico, es una gran ocasión para expandir el mercado y los negocios (el mercado del hiperaprendizaje);

c) porque no tienen interés en distribuir equitativamente ese recurso tan valioso que es el conocimiento y tienen sus propios mecanismos de apropiación (la educación privada de elite);

d) porque la hegemonía a la que aspira y necesita toda clase dominante no se produce más desde la escuela ni a través de acciones explícitas de inculcación, sino a través "de las cosas" y de la incorporación de la mayoría de la población como consumidores de la industria cultural de masas.

Comparto totalmente con Tedesco su planteamiento acerca de las dos ideas rectoras de un programa educativo del siglo XXI: el aprender a aprender y el aprender a vivir juntos.

\footnotetext{
${ }^{26}$ No puedo resistirme a la tentación de asociar la tesis del fin de la transmisión cultural (que no es sostenida por Tedesco) con otros razonamientos análogos, muy populares durante los últimos veinte años. En efecto, pareciera otro retoño de un esquema de pensamiento "fin/post" muy de moda en ciertos círculos intelectuales. Fin de la modernidad, fin de lo social, fin de la historia, todas constataciones que por lo general terminan en una especie de pensamiento incapaz de definir qué es lo que reemplaza a lo que termina. Por lo tanto, lo nuevo es definido simplemente como post; es decir, como "lo" que viene después de (la modernidad, la historia, la burocracia, la transmisión cultural, etc.). La indeterminación que resulta del uso y abuso del prefijo no podría ser mayor
} 
En otras palabras, pese a todas las crisis y todos los finales (de la historia, de la verdad, del método, de las instituciones $\mathrm{y}$, por último, de lo social), es preciso reivindicar el derecho de los humanos a construir colectivamente su propia historia conforme a valores que no son eternos, sino delicadas construcciones sociales que requieren determinadas condiciones de realización práctica. Si bien es lícito no renunciar a determinados ideales colectivos, la historia enseña que los ideales no se imponen simplemente por sus cualidades intrínsecas. Cada conquista (en el sentido de la humanización) de la sociedad humana es en gran parte el desenlace de una lucha y un conflicto. Es más, la lucha constituye el motor de la historia. Tomemos un ejemplo que viene al caso. Mucho se habla y se dice del fin de "lo social" y el debilitamiento de las instituciones. Pero por lo general se tiende a presentar estos fenómenos como hechos inevitables, fruto de una especie de evolución natural de las cosas. De este modo se elude todo lo que en la historia hay de política o de voluntad colectiva y organizada. Así, por ejemplo, no basta constatar y demostrar que hoy la escuela (pública) es débil, que sufre un proceso de desinstitucionalización, etc., sino se hace necesario rendir cuentas de este fenómeno que no tiene nada de natural ni de inevitable. Por el contrario, debilitamiento de la escuela (de la escuela pública habría que agregar, no de las escuelas privadas de elites que cada día gozan de mejor salud) es también el resultado de políticas activas o pasivas formadas por acciones y omisiones bien concretas que es preciso analizar y denunciar (por ejemplo, de desfinanciamiento, de abandono, de reformas equivocadas, etc.). De este modo, la desinstitucionalización deja de ser una fatalidad a la que hay que adaptarse sin más, sino un proceso bien real con sus protagonistas, intereses, relaciones de fuerza, conflicto, etc.

No es necesario describir aquí el contenido de estos ejes de acción (aprender a aprender y aprender a vivir juntos), que responden a la dimensión cognitiva el primero y a la cultural el segundo. Lo que interesa destacar es, en última instancia, que el desarrollo de esos pilares supone introducir en la escuela la posibilidad de vivir experiencias que no se producen "naturalmente" en el espacio externo a la escuela. Y no sólo no se producen en el espacio externo de la escuela, sino que se produce otra educación, otra construcción de subjetividad, opuesta a los valores que asumimos como más humanos. Porque la vida educa, el trabajo educa, el mercado educa, los medios masivos de educación inculcan valores, predisposiciones, criterios de verdad, gustos, criterios de evaluación, de apreciación y de acción. Por eso es preciso recordar, justamente con Tedesco, que la escuela, dadas determinadas condiciones que es preciso analizar y conquistar, debe constituirse en un lugar de contra cultura (o de cultura contrahegemónica (Tedesco J.C., 2001). $Y$ todo esto hay que hacerlo sin caer en el pedagogicismo ingenuo propio de la década de los 60's (la escuela liberadora). Por eso hay que ser realistas y proponerse una política de la escuela capaz de proveer a esta institución de todos los recursos, no sólo financieros, sino también institucionales, culturales, pedagógicos, didácticos, como para que pueda competir con éxito con los medios de comunicación en esta formidable tarea de construir sujetos humanos conscientes y críticos, pero también sabios y competentes. Para esto último es preciso garantizar a las nuevas generaciones la transmisión de las herramientas más poderosas de la cultura acumulada por la humanidad (esto es lo que hacen algunos colegios de las elites, al mismo tiempo que pueden estar reforzando valores tales como el egoísmo, el consumismo, la competencia, el cinismo, la tolerancia frente a las desigualdades y a las miserias del mundo). Por eso en las escuelas públicas, esto es, las escuelas donde predomina la lógica del interés general y la inclusión social, deberían favorecer la apropiación de lo mejor de la cultura disponible, de esa parte de la cultura que tiene esa cualidad creativa e innovadora. Por eso son importantes los lenguajes básicos, la lógica, el conocimiento de la teoría entendida como conocimiento para producir conocimiento y no para reproducirlo. Quienes más se apropian de la herencia cultural están en mejores condiciones de recrear la cultura sobre bases nuevas y 
en función de las nuevas posibilidades abiertas por el desarrollo de la ciencia y la tecnología modernas. Pero quienes queremos no sólo el progreso, entendido como liberación del hombre de los determinismos que devienen de la naturaleza, sino también de la dominación de unos hombres sobre otros hombres, debemos incluir en el "programa de socialización" no sólo las herramientas que le permiten al hombre reforzar su poder sobre la naturaleza, sino las herramientas intelectuales y morales (los valores universales históricamente construidos) que le permitan liberarse de las otras dominaciones (la del género, la riqueza, la etnia, la religión, etc., etc.). Estas dos liberaciones (la material y la cultural y social) serán el producto de una voluntad colectiva y de la fuerza y eficacia de las instituciones que seamos capaces de diseñar y desarrollar. La educación espontánea de las cosas (la del mercado y sus leyes, la de la escasez y la exclusión, la de la explotación, la de los medios orientados a la búsqueda de la ganancia y el rating, etc.) tenderá a la reproducción de una hegemonía que es tanto más poderosa cuanto menos se presenta como el resultado de una inculcación y puede entonces rodearse de todas las cualidades de lo obvio y natural).

Por cierto, tiene razón Tedesco cuando sospecha que "estas reflexiones sobre el papel de la educación y de la escuela pueden ser consideradas como ingenuamente voluntaristas" y por eso también es lícito preguntarse, como lo hace él "¿cómo podría la educación y sus formas institucionales tradicionales desarrollar una acción contracultural" (JCT en Propuesta). Es claro que no se responde a esta estratégica cuestión simplemente levantando la bandera de los valores y la moral. Para liberarse de los determinismos es una condición indispensable la conciencia de la necesidad. En otras palabras, no se superan los determinismos negándolos, cuando todas las evidencias sociológicas están allí para mostrarnos que existen fuertes relaciones probabilísticas entre el hecho de ocupar un determinado lugar en una estructura (de distribución de riqueza, espacial, familiar, cultural, etc.) y determinados comportamientos (desde el voto, las preferencias estéticas, los gustos y consumos culturales, hasta el establecimiento educativo al que se concurre y el promedio de notas en las evaluaciones de lengua y matemáticas).

\section{Para entender mejor}

No me resulta fácil sintetizar mis acuerdos y desacuerdos con los planteos de Tedesco. Sin embargo, puedo resumir mis reflexiones alrededor de algunas proposiciones:

a) Vivimos una época de cambio radical. El capitalismo ha ingresado en una nueva fase de su desarrollo y parece reinar tanto en las cosas como en las conciencias.

b) La hegemonía, entendida como dominación, se produce y reproduce en forma espontánea. Es el peso de las nuevas relaciones sociales el que "produce subjetividad".

c) La realización más completa de la hegemonía nunca es total. Los problemas que no resolvieron los "socialismos reales" no los resuelve el capitalismo. La cuestión social adquiere características cada vez más dramáticas.

d) El dominio sobre las cosas y las conciencias no excluye la presencia de múltiples resistencias. Estas adquieren día a día protagonistas y formas inéditas y hasta cierto punto imprevisibles. La salud del capitalismo convive con el conflicto y la lucha.

e) La escuela pública puede constituirse en un espacio contracultural, a condición que sus protagonistas se lo propongan. Su fuerza dependerá de la cantidad y calidad de recursos de diverso tipo que logre movilizar y de la inteligencia que use para emplearlos. 
Por último, hay que tener presente que no vivimos "tiempos normales". Decía Durkheim (1974) que "cuando una sociedad se encuentra en un estado de estabilidad relativa, de equilibrio temporario (...) los únicos problemas apremiantes que se plantean son problemas de aplicación", y agregaba a continuación: "No tengo que deciros que esa seguridad intelectual y moral no es propia de nuestro siglo; en ello está a la vez su miseria y su grandeza". El momento que vivimos tampoco se caracteriza por la estabilidad y la seguridad. La crisis actual, es en gran medida una crisis de sentido. Por eso, la actitud más conveniente en estas circunstancias es la de la perplejidad sistemática.

Pero pese a la novedad y complejidad de la situación no debemos renunciar al ejercicio de la razón. Una razón que no es una razón abstracta y eterna, sino histórica y contingente, pero al mismo tiempo operativa y eficiente, tanto para producir explicaciones plausibles como para orientar la acción. Para ello no estamos completamente desarmados. Podemos movilizar las mejores armas que nos ofrece la tradición intelectual de las ciencias humanas y sociales. Pero estas armas (teorías, sistemas conceptuales, estrategias metodológicas, etc.) no están allí listas para ser utilizadas y "aplicadas". Ellas tienen que ser adecuadas a las particularidades de los desafíos actuales, y esta es una tarea que excede las capacidades del intelectual tradicional individual. Por eso, es más urgente que nunca darle forma a ese "intelectual colectivo", único actor que está en condiciones de enfrentar con cierta probabilidad de éxito la inmensa tarea de proveer explicaciones plausibles necesarias para orientar la acción en estos "tiempos difíciles que vivimos". El trabajo de Tedesco es un aporte a esta construcción necesaria y este es quizás el mejor elogio que se le puede dispensar.

\section{Bibliografía citada}

BOURDIEU, Pierre, "Espíritus de Estado", en Sociedad No. 8, Facultad de Ciencias Sociales, Universidad de Buenos Aires, Buenos Aires, abril de 1996.

BOLTANSKI, Luc y CHIAPELLO, Ėve, Le nouvel esprit du capitalisme. Gallimard, Paris, 1999.

BORGES, Jorge Luis, Prosa completa. Bruguera, Buenos Aires, Volumen 1, 1980.

DURKHEIM, Emilio, Educación y sociología. Shapire, Buenos Aires, 1974.

ELIAS, Norberto, Potere e civiltà. II Mulino, Bologna, 1983.

, La civilización de los padres y otros ensayos. Norma, Bogotá, 1998.

PERELMAN, Lewis, "L'école actuelle est aussi productive et novatrice qu'un kolkhoze", en Courrier International No. 255, del 21 al 27 de septiembre de 1995; de un texto aparecido originalmente en la revista mensual Wired (EEUU). Trad. de E. Tenti Fanfani (mimeo).

TEDESCO, Juan Carlos, "Educación y hegemonía en el nuevo capitalismo. Algunas hipótesis de trabajo", en Propuesta Educativa, FLACSO, Buenos Aires, 2002.

TENTI FANFANI, Emilio, "Socialización", en ALTAMIRANO, Carlos (Ed.), Términos críticos. Diccionario de sociología de la cultura. Paidós, Buenos Aires, 2002.

WEBER, Max, Economía y sociedad. Fondo de Cultura Económica, México, 1982. 